\title{
Effect of Confinement of Anionic Organic Ultraviolet Ray Absorbers into Two-dimensional Zinc Hydroxide Nitrate Galleries
}

\author{
Ana Cristina T. Cursino, ${ }^{a}$ Antonio Salvio Mangrich, ${ }^{b}$ José Eduardo F. da Costa \\ Gardolinski, $^{c}$ Ney Mattoso ${ }^{d}$ and Fernando Wypych ${ }^{*, a}$
}

\author{
${ }^{a}$ CEPESQ - Research Centre of Applied Chemistry, Department of Chemistry, \\ ${ }^{b}$ LABPAM - Laboratory of Environmental Projects and Processes, Department of Chemistry, \\ ${ }^{c}$ LAMIR - Laboratory for Analysis of Minerals and Rocks, Department of Geology and

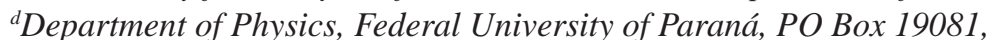 \\ 81531-980 Curitiba-PR, Brazil
}

\begin{abstract}
Espécies aniônicas absorvedoras de radiação ultravioleta (UV) (4-metoxibenzoato, $\mathrm{N}$-acetilantranilato, 4-metoxicinamato e 4,4'-diamino-2,2'-estilbenodissulfonato) foram intercaladas em hidroxinitrato de zinco pelo método de co-precipitação ou reação de troca aniônica topotática. A intercalação foi confirmada por difratometria de raios X de pó (XRPD), espectroscopia na região do infravermelho com transformada de Fourier (FTIR), análise térmica (TGA/DTA), microscopia eletrônica de varredura (SEM), difração de elétrons em área selecionada (SAED), análise elementar e espectroscopia eletrônica na região do ultravioleta-visível (UV-Vis). Na reação de co-precipitação uma intercalação completa foi observada, enquanto na reação de troca aniônica os íons nitrato só foram parcialmente substituídos pelos ânions orgânicos. Após a intercalação, a capacidade de absorção de radiação UV foi similar à dos sais e ácidos sólidos, sendo o efeito atribuído ao confinamento das espécies aniônicas na galeria bidimensional da matriz hospedeira. Essa observação abre novas oportunidades para o uso de matrizes lamelares alternativas para a imobilização de ânions, na formulação de protetores solares.
\end{abstract}

Anionic ultraviolet (UV) ray absorbers (4-methoxybenzoate, $\mathrm{N}$-acetylanthranilate, 4-methoxycinnamate and 4,4'-diamino-2,2'-stilbenedisulfonate) were intercalated into zinc hydroxide nitrate, either by direct alkaline co-precipitation or topotactic exchange reactions. The intercalation was confirmed by X-ray powder diffractometry (XRPD), Fourier transform infrared spectroscopy (FTIR), thermal analysis (TGA/DTA), scanning electron microscopy (SEM), selected area electron diffraction (SAED), elemental analysis and ultraviolet visible (UV-Vis) spectroscopy. In the co-precipitation reactions full intercalation was achieved, while during the exchange reactions nitrate anions were not completely replaced by the organic anions. After the intercalation, the UV absorption capacity was similar to that of the solid salts and acids, the effect being attributed to the confinement of the anionic species in the host two-dimensional gallery. This observation opens new opportunities for the use of organic anions immobilized in alternative layered matrixes for the formulation of sunscreens.

Keywords: zinc hydroxide nitrate, UV ray absorbers, sunscreens, layered materials, intercalation

\section{Introduction}

Health problems related to the exposure to solar ultraviolet (UV) radiation can be minimized by the use of sunscreens and other cosmetic filters. These products are regularly used by millions around the globe. Because of

*e-mail: wypych@ufpr.br their frequent and long-term use, special attention has been devoted to the efficiency and safety of these formulations. ${ }^{1}$

UV ray absorbing organic molecules are widely employed as active ingredients of sunscreens. Among such substances are anthranilates and cinnamates. ${ }^{2}$ Although there are a large number of anthranilates (also known as ortho-aminobenzoates), only two of them are commonly found in commercial products: homomethyl- $N$-acetyl- 
anthranilate and methyl-anthranilate. As the UVA ray absorption of these compounds is low, they are usually used together with other UV absorbers. These compounds present good stability and solubility in topical preparations, with absorption maxima around $336 \mathrm{~nm}$ for the ortho and $300 \mathrm{~nm}$ for the para molecules. ${ }^{3}$ On the other hand, the cinnamates constitute a larger group of compounds, seventeen of them having been approved as sunscreens in Europe and four in the United States. The cinnamates are insoluble in water but highly soluble in alcohol, acetone and benzene. They act as absorbers in the UVB region, with maxima around $300 \mathrm{~nm} .{ }^{4,5}$

Even though the use of UV ray absorber molecules, due to their high affinity for the stratum corneum, is very widespread, they can be easily absorbed by the body, leading to phototoxic and allergic reactions. ${ }^{6-8}$ To prevent the direct contact of such molecules with human tissues, they can be intercalated into layered structures, such as layered hydroxide salts (LHSs) ${ }^{9}$ and other layered materials. ${ }^{10-12}$

The structure of LHSs is derived from that of a generic layered hydroxide $\left(\mathrm{M}(\mathrm{OH})_{2}\right)$, where a fraction of the hydroxyl sites are substituted by other anions or by water molecules, resulting in a structure with positively charged layers that are electrically balanced by intercalated anions. Their general formula is $\mathrm{M}^{2+}(\mathrm{OH})_{2-\mathrm{x}}\left(\mathrm{A}^{\mathrm{n}-}\right)_{\mathrm{x} / \mathrm{n}} \cdot \mathrm{yH}_{2} \mathrm{O}$, where $\mathrm{M}^{2+}$ is a metal cation $(\mathrm{Mg}, \mathrm{Ni}, \mathrm{Zn}, \mathrm{Ca}, \mathrm{Cd}, \mathrm{Co}$ and $\mathrm{Cu}$ ) and $\mathrm{A}$ is the $\mathrm{n}^{-}$charged anion, called the counter-ion $\left(\mathrm{Cl}^{-}, \mathrm{NO}_{3}^{-}\right.$, $\mathrm{SO}_{4}{ }^{2-}$ and $\left.\mathrm{H}_{3} \mathrm{CCOO}^{-}\right){ }^{13-16}$ Due to the structural characteristics of LHSs, various kinds of anions can be intercalated, from simple monoatomic species to complex molecules.

The main goal of this work is to further study the intercalation of UV radiation absorbers into LHSs. This could possibly give rise to a new generation of sunscreens that could significantly reduce the absorption of the active molecules by the human skin, avoiding the cause of many allergic reactions and also slowing their photodegradation.

\section{Experimental}

\section{Synthesis of zinc hydroxide nitrate}

The synthesis of zinc hydroxide nitrate (ZHN) was carried out following a procedure described elsewhere. ${ }^{17,18}$

In short, it was prepared by the slow addition of an aqueous $\mathrm{NaOH}$ solution $\left(1 \mathrm{~mol} \mathrm{~L}^{-1}\right)$ into $70 \mathrm{~mL}$ of aqueous solution containing $17.5 \mathrm{mmol}$ of $\mathrm{Zn}\left(\mathrm{NO}_{3}\right)_{2} \cdot 6 \mathrm{H}_{2} \mathrm{O}$, under magnetic stirring, with the final $\mathrm{pH}$ adjusted to around 6.5. The solid was separated by centrifuging at $4000 \mathrm{rpm}$ for $5 \mathrm{~min}$, followed by extensive washing with distilled water (5 times). The final white solid was dried under vacuum at $60{ }^{\circ} \mathrm{C}$ for $24 \mathrm{~h}$. The prepared ZHN was used as a matrix for the intercalation of several organic UV ray absorber anions, whose acids are shown in Figure 1.

\section{Preparation of the intercalation compounds}

\section{Exchange reaction}

An intercalation compound with 4-methoxybenzoate was prepared by the slow addition of $50 \mathrm{~mL}$ of an aqueous solution of $\mathrm{NaOH}\left(1 \mathrm{~mol} \mathrm{~L}^{-1}\right)$ to $70 \mathrm{~mL}$ of a suspension containing $4.7 \mathrm{mmol}$ of 4-methoxybenzoic acid (Figure 1a) in decarbonated water, to obtain a solution of sodium 4-methoxybenzoate salt. To this solution, ZHN ( $2 \mathrm{mmol})$ was added and the suspension was magnetically stirred at $60{ }^{\circ} \mathrm{C}$ for 4 days, before being centrifuged and extensively washed with distilled water (4 times). The final white solid (ZHN-MB) was dried under vacuum at $60^{\circ} \mathrm{C}$ for $24 \mathrm{~h}$. The same procedure was followed to synthesize the product with $N$-acetylanthranilic acid (Figure 1b, ZHN-NAA).

\section{Synthesis by co-precipitation}

As some organic anions do not have the sufficient thermodynamic driving forces to displace the intercalated nitrate anions from the ZHN structure, new attempts

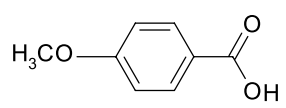

(a) 4-Methoxybenzoic acid

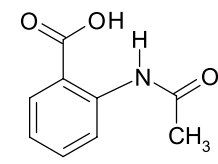

(b) $N$-Acetylanthranilic acid

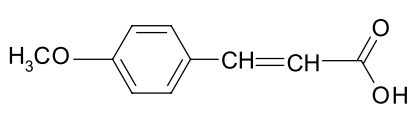

(c) 4-Methoxycinnamic acid<smiles>Nc1ccc(C=C=Cc2ccc(N)cc2S(=O)(=O)O)c(S(=O)(=O)O)c1</smiles>

(d) 4,4'-Diamino-2,2'-stilbenedisulfonic acid

Figure 1. Organic UV ray absorbing molecules used in the intercalation reactions with ZHN. 
were made to produce these compounds by direct co-precipitation. The intercalation compound with 4-methoxycinnamate (Figure 1c) was prepared by dissolving $2.5 \mathrm{mmol}$ of 4-methoxycinnamic acid in $20 \mathrm{~mL}$ of an aqueous solution of $\mathrm{NaOH}\left(0.4 \mathrm{~mol} \mathrm{~L}^{-1}\right)$. To this, $20 \mathrm{~mL}$ of a solution containing $7.5 \mathrm{mmol}$ of $\mathrm{Zn}\left(\mathrm{NO}_{3}\right)_{2} \cdot 6 \mathrm{H}_{2} \mathrm{O}$ was slowly added and the final $\mathrm{pH}$ was adjusted to around 7 by the addition of a $\mathrm{NaOH}$ $\left(0.4 \mathrm{~mol} \mathrm{~L}^{-1}\right)$ solution. The suspension was magnetically stirred at room temperature for 3 days, before being centrifuged and washed 5 times with distilled water. The final white solid (ZHN-MC) was dried under vacuum at $60{ }^{\circ} \mathrm{C}$ for $24 \mathrm{~h}$. The same procedure was followed to synthesize the product with 4,4'-diamino-2,2'stilbenedisulfonic acid (Figure 1d), denoted ZHN-DSD.

\section{Characterization}

X-ray powder diffraction (XRPD) patterns were recorded with a Shimadzu XDR-6000 instrument using $\mathrm{CuK}_{\alpha}$ radiation $(\lambda=1.5418 \AA)$ in Bragg-Brentano geometry, with a dwell time of $1^{\circ} \mathrm{min}^{-1}$. The samples were placed and oriented by hand by pressing on neutral glass sample holders.

The FTIR spectra were recorded with a BioRad FTS 3500GX and a Bomem Michelson MB100 spectrophotometers, using approximately $1 \%$ sample in $100 \mathrm{mg}$ of spectroscopic grade $\mathrm{KBr}$. The pellets were pressed at 10 ton. The measurements were performed in transmission mode with accumulation of 32 scans and recorded with a nominal resolution of $2 \mathrm{~cm}^{-1}$.

Thermal analyses (thermogravimetry-TGA and differential thermal analysis-DTA) were performed in $150 \mu \mathrm{L}$ alumina crucibles with a Mettler-Toledo TG/ SDTA 851 e Thermoanalyser under a $50 \mathrm{~mL} \mathrm{~min}^{-1}$ oxygen flow, at a heating rate of $10{ }^{\circ} \mathrm{C} \mathrm{min}^{-1}$, in the range of $30-1000{ }^{\circ} \mathrm{C}$.

The diffuse reflectance ultraviolet-visible (DRUVVIS) spectra were obtained at room temperature in the region of 240-800 $\mathrm{nm}$, at intervals of $0.5 \mathrm{~nm}$, with a Shimadzu UV-2401PC spectrophotometer equipped with a Model 240-52454-01 integration sphere.

Scanning electron microscopy (SEM) analyses of the samples were carried out (after metallization with gold) with a JEOL JSM 6360 LV microscope operating at $15 \mathrm{kV}$. Selected area electron diffraction (SAED) measurements were performed with a JEOL JEM 1200 EX-II transmission electron microscope (TEM) operating at $80 \mathrm{kV}$ for pure $\mathrm{HZN}$ and $50 \mathrm{kV}$ for the compounds obtained by co-precipitation. Calibration of the electron diffraction to SAED measurements was carried out using an Au sample as reference.

\section{Results and Discussion}

The XRPD patterns of ZHN and the compound prepared by co-precipitation with 4,4'-diamino-2,2'stilbenedisulfonic acid are shown in Figure 2.

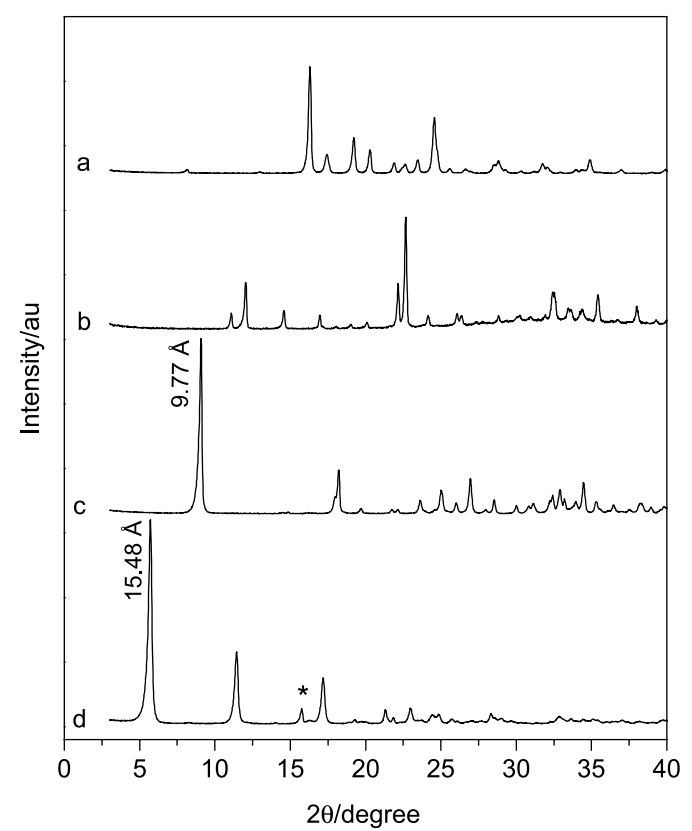

Figure 2. XRPD patterns of 4,4'-diamino-2,2'-stilbenedisulfonic acid (a), 4',4-diamino-2,2'-stilbenedisulfonic acid sodium salt (b), ZHN (c) and ZHN-DSD (d).

The product obtained from the alkaline precipitation shows the formation of a crystalline phase of the zinc hydroxide nitrate $\left(\mathrm{Zn}_{5}(\mathrm{OH})_{8}\left(\mathrm{NO}_{3}\right)_{2} \cdot 2 \mathrm{H}_{2} \mathrm{O}=\mathrm{ZHN}\right)$, identified by the JCPDS file number 24-1460. ${ }^{19}$ The diffraction pattern shows an intense reflection due to the (200) plane of the monoclinic structure, with a basal spacing of $9.77 \AA$ (Figure 2c).

For the direct synthesis from 4,4'-diamino-2,2'stilbenedisulfonic acid in the presence of zinc nitrate through alkaline co-precipitation, the basal spacing of the product (ZHN-DSD) was measured as $15.48 \AA$ (Figure 2d). This indicates the presence of the organic anion between the inorganic layers of the matrix, with a basal expansion of $5.71 \AA$ from the original compound. The preservation of the layered structure of the matrix is confirmed by the presence of the basal reflections, which are uniformly distributed between $5^{\circ}$ and $35^{\circ}$ (in $2 \theta$ ). In the region of $16^{\circ}$ (in $2 \theta$ ), the small peak indicated by an "*" is of one unknown phase, but it is not attributed to the 4,4'-diamino-2,2'-stilbenedisulfonic acid.

The FTIR spectra of the same compounds are shown in Figure 3.

The FTIR spectrum of the ZHN (Figure 3c) presents an intense band at $1384 \mathrm{~cm}^{-1}$, characteristic of the nitrate ion with 


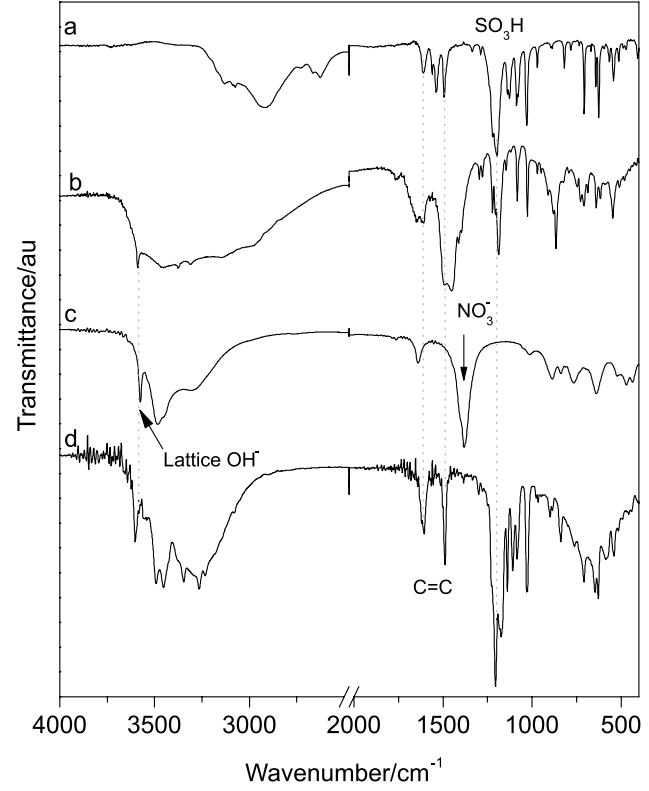

Figure 3. FTIR spectra of 4,4'-diamino-2,2'-stilbenedisulfonic acid (a), 4',4-diamino-2,2'-stilbenedisulfonic acid sodium salt (b), ZHN (c) and ZHN-DSD (d).

$D_{3 \mathrm{~h}}$ symmetry $\left(v_{3} \text { mode }\right)^{18}$. A broad band around $3500 \mathrm{~cm}^{-1}$ is also seen, attributed to the vibration of the hydroxyl groups, which have multiple hydrogen bonds with physisorbed/ intercalated water molecules. A narrow band present at $3575 \mathrm{~cm}^{-1}$ is also attributed to hydroxyl groups, but in this case from the crystal lattice, with a well defined vibration energy. ${ }^{20}$

The FTIR spectrum of the 4,4'-diamino-2,2'stilbenedisulfonic acid (Figure 3a) presents a band between 3140 and $2920 \mathrm{~cm}^{-1}$ that is attributed to the axial deformation of aromatic $\mathrm{N}-\mathrm{H}$ and $\mathrm{C}-\mathrm{H}$ aliphatic groups. Normally the symmetric and asymmetric axial deformations of the $\mathrm{S}=\mathrm{O}$ groups are visible around 1350$1342 \mathrm{~cm}^{-1}$ and $1165-1150 \mathrm{~cm}^{-1}$, respectively. However, it was not possible to identify these bands because such values are due to the anhydrous form of the acid, which promptly hydrates to a hydronium-sulfonate, thus giving rise to bands around $1230-1120 \mathrm{~cm}^{-1} .{ }^{21}$ These hydrated form bands are present in the acid at $1200 \mathrm{~cm}^{-1}$ and also in its sodium salt (Figure 3b) and in the ZHN-DSD compound (Figure 3d). The axial deformation bands of the aromatic $\mathrm{C}=\mathrm{C}$ groups around 1613 and $1482 \mathrm{~cm}^{-1}$ seen in the acid, its sodium salt and, most importantly, in the ZHN-DSD compound, further confirm the intercalation of the organic anion.

To study the behavior of the product in the ultravioletvisible region, DRUV-VIS spectroscopy was conducted (Figure 4). The Kubelka-Munk function was applied to the study of optically thick samples, where more than $50 \%$ of the light is reflected and less than $20 \%$ is transmitted. ${ }^{22}$ The experimental reflectance spectra were converted by the reemission function of Kubelka-Munk, defined as:
$f(K M)=(1-R)^{2} / 2 R=k / s$, where $R$ is the reflectance, $k$ is the absorption coefficient and $\mathrm{s}$ is the dispersion coefficient. ${ }^{23}$ Assuming that the dispersion coefficient varies minimally as a function of the wavelength, the reemission function areas and the absorption function areas of the spectra should be very near each other.

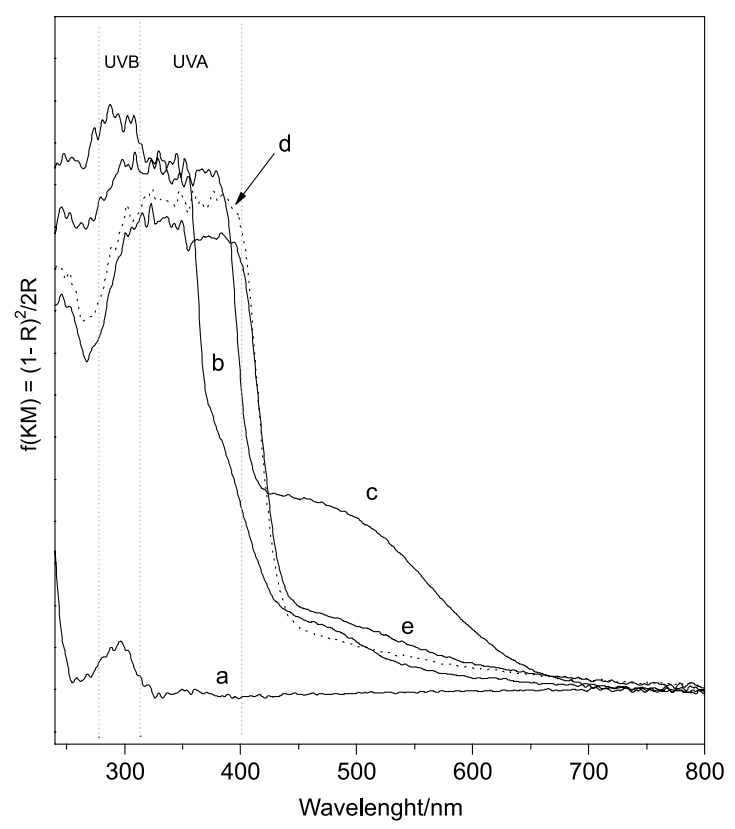

Figure 4. DRUV-VIS spectra of ZHN (a), 4,4'-diamino-2,2'stilbenedisulfonic acid (b), 4',4-diamino-2,2'-stilbenedisulfonic sodium salt (c), ZHN-DSD (d) and ZHN-DSD after $2 \mathrm{~h}$ stirring in water (e).

The yellowish 4,4'-diamino-2,2'-stilbenedisulfonic acid has an absorption maximum in the region around 250-354 nm (Figure 4b), covering the entire UVB region and part of the UVA region. Its orange colored sodium salt absorbs in the region around 240-379 nm, covering the UVC to UVA regions (Figure 4c).

The ZHN-DSD product has a light beige color, which can be considered esthetically more pleasing and thus more usable than the strong-colored free acid and its sodium salt. It has a significant absorption in the whole ultraviolet region, from UVA to UVC (Figure 4d), slightly less intense in the higher wavelengths than the free sodium salt due to the dilution effect after intercalation into the ZHN layered material. The organic molecule slightly increases its range to absorb UV light, and this effect can be interpreted on the basis of the spatial confinement of the anionic species in the interlayer LHS space, lowering the symmetry of the intercalated anion in comparison to the molecules in the solid salt or acid, and also to supramolecular host-guest interactions (electrostatic attraction, hydrogen bonding and van der Waals forces). ${ }^{24,25}$ 
The stability of the ZHN-DSD product was tested by stirring in water for $2 \mathrm{~h}$. After this treatment, the absorption in the ultraviolet region was virtually unchanged (Figure 4e). In addition, the XRPD pattern of this product (not shown) showed no changes in relation to the original product.

Thermal analysis (TGA/DTA) results from ZHN (not shown) reveal a complex decomposition profile with a series of endothermic events around $200{ }^{\circ} \mathrm{C}(129,163$, 214 and $262{ }^{\circ} \mathrm{C}$ ), attributed to loss of water, both adsorbed and structural, which comprises $6 \%$ of the total mass up to $131{ }^{\circ} \mathrm{C}$. Between 131 and $552{ }^{\circ} \mathrm{C}$ a mass loss of $27 \%$ occurs, attributed to the matrix dehydroxylation along with nitrate decomposition. ${ }^{26}$ The mass losses are consistent with the formula $\mathrm{Zn}_{5}(\mathrm{OH})_{8}\left(\mathrm{NO}_{3}\right)_{2} \cdot 1.74 \mathrm{H}_{2} \mathrm{O}$, close to the theoretical formula.

TGA/DTA measurements were performed to estimate the composition of the intercalation compounds (Figure 5).

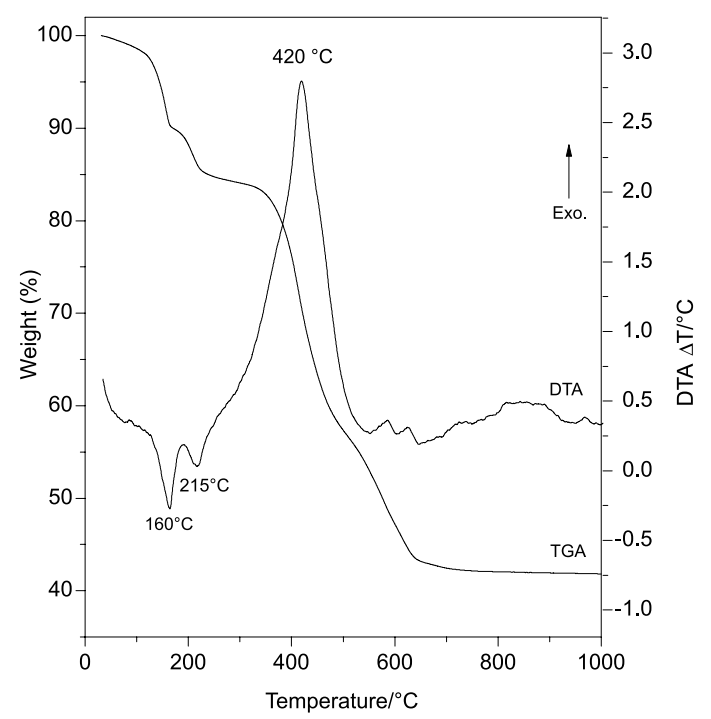

Figure 5. TGA/DTA curves for the ZHN-DSD compound.

The thermal analysis curves of ZHN-DSD show three main thermal events. The first two correspond to the removal of physisorbed/intercalated water molecules, associated with two DTA peaks at 160 and $215^{\circ} \mathrm{C}$. The third thermal event is attributed to the oxidation of organic matter and dehydroxylation of the layered matrix, producing $\mathrm{ZnO}$, as attested by XRD (not shown). With this information, it was possible to estimate the composition of the compounds as being $\mathrm{Zn}_{5}(\mathrm{OH})_{8}\left(\mathrm{NO}_{3}\right)_{0.04}\left(\mathrm{C}_{14} \mathrm{H}_{12} \mathrm{~N}_{2} \mathrm{O}_{6} \mathrm{~S}_{2}\right)_{0.98} \cdot 0.84 \mathrm{H}_{2} \mathrm{O}$, close to the stoichiometric value. The thermal stability of ZHN-DSD is around $250{ }^{\circ} \mathrm{C}$, under dynamic heat conditions.

Morphological analyses of the ZHN (Figure 6a) and ZHN-DSD (Figure 6b) were performed by SEM. The precursor ZHN is characterized by tabular particles with well defined corners and a wide size distribution, in accordance to what has already been reported for similar compounds. ${ }^{16}$ The co-precipitated ZHN-DSD compound was also characterized by tabular particles with well defined corners, these however being much larger than those of the ZHN and very fragmented, due to the magnetic stirring.

Figure 7 presents the XRPD patterns of the ZHN derivatives with 4-methoxybenzoate, ZHN-MB (Figure 7b), 4-methoxycinnamate, ZHN-MC (Figure 7c) and $\mathrm{N}$-acetylanthranilate, ZHN-NAA (Figure 7d).

The basal spacing of the ZHN-MB and ZHN-MC compounds increased from the original $9.77 \AA$ of the pristine ZHN to 18.67 and $20.13 \AA$, respectively. This strongly indicates the substitution of the originally intercalated nitrate anion by the corresponding organic anions employed. It can also be seen that these products are possibly contaminated with phases presenting various degrees of hydration or formation of stage intermediate phase, characterized by low intensity peaks at 26.5 and $26.9 \AA$ for ZHN-MC and ZHN-MB, respectively. The X-ray diffraction patterns of the ZHN-NAA compound (Figure 7d) show no clear distinction in the basal distances from the original ZHN, suggesting that the organic anion was not intercalated. This is probably due to the incompatibility between the positions of the negative charges in the $N$-acetylanthranilate and the positive charges in the ZHN structure. However, no diffraction peaks due to the free acid or its sodium salt could be detected.

The FTIR spectra of 4-methoxycinnamate, 4-methoxybenzoate, $\mathrm{N}$-acetylanthranilate and their $\mathrm{ZHN}$ derivatives can be seen in Figure 8. Bands attributed to vibrational modes from the $\mathrm{N}$-acetylanthranilate anion are present in the FTIR spectrum of the ZHN-NAA product (Figure 8g). In this case, the bands at 1515 and $1415 \mathrm{~cm}^{-1}$ are attributed to the asymmetric and symmetric carboxylate stretching modes. Between 2900 and $2850 \mathrm{~cm}^{-1}$, weak bands from the axial deformation of methyl $\mathrm{C}-\mathrm{H}$ bonds are also present. In addition, the characteristic nitrate band at $1384 \mathrm{~cm}^{-1}$ is still present. The presence of these organic bands and the fact there was no change in the basal spacing of the matrix suggests that the $N$-acetylanthranilate molecules are adsorbed on the surface of the ZHN particles.

For the ZHN-MB and ZHN-MC compounds, the presence of the intercalated organic UV ray absorbing anions can be attested by their FTIR spectra (Figures 8c and 8e). Around 1540 and $1420 \mathrm{~cm}^{-1}$, bands attributed to carboxylate asymmetric and symmetric stretching modes are observed, as well as bands between 3070 and $2840 \mathrm{~cm}^{-1}$, attributed to the axial deformation of $\mathrm{C}-\mathrm{H}$ groups in aromatic rings and methyl groups, ${ }^{27}$ alongside other bands 

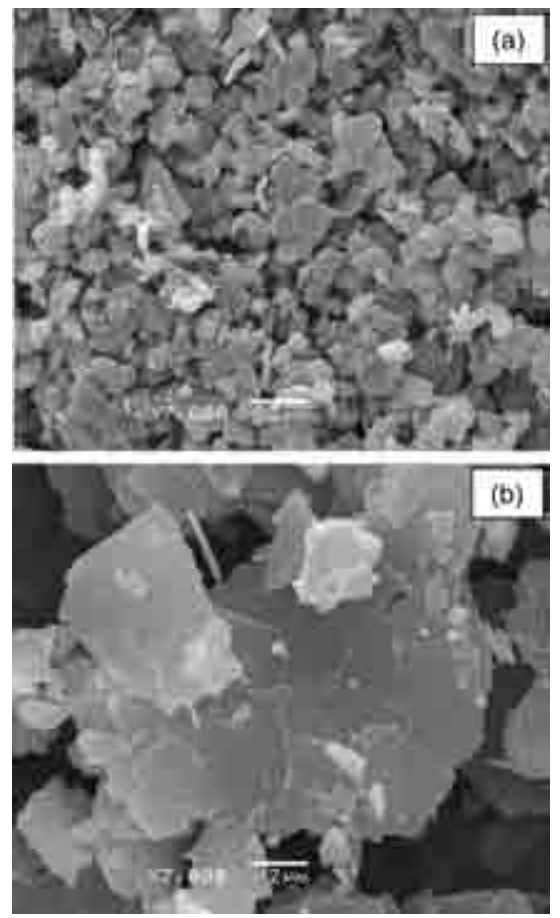

Figure 6. SEM images of ZHN (a) and ZHN-DSD (b).

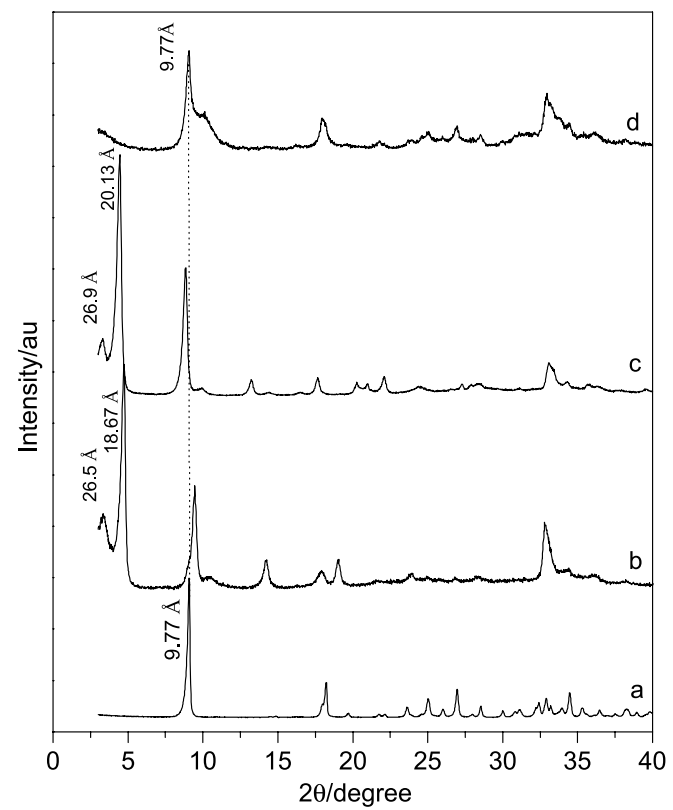

Figure 7. XRPD patterns of ZHN (a), ZHN-MB (b), ZHN-MC (c) and ZHN-NAA (d).

presented in Table 1. Bands attributed to the inorganic matrix are also present, like the broad signal between 3600 and $3350 \mathrm{~cm}^{-1}$, characteristic of lattice hydroxyl groups.

The thermal profiles of the ZHN-MB and ZHN-MC compounds (not shown) are very similar, presenting two major events, the first one attributed to water loss (endothermic event around $150{ }^{\circ} \mathrm{C}$ ) and the second one attributed to the dehydroxylation of the matrix and burning

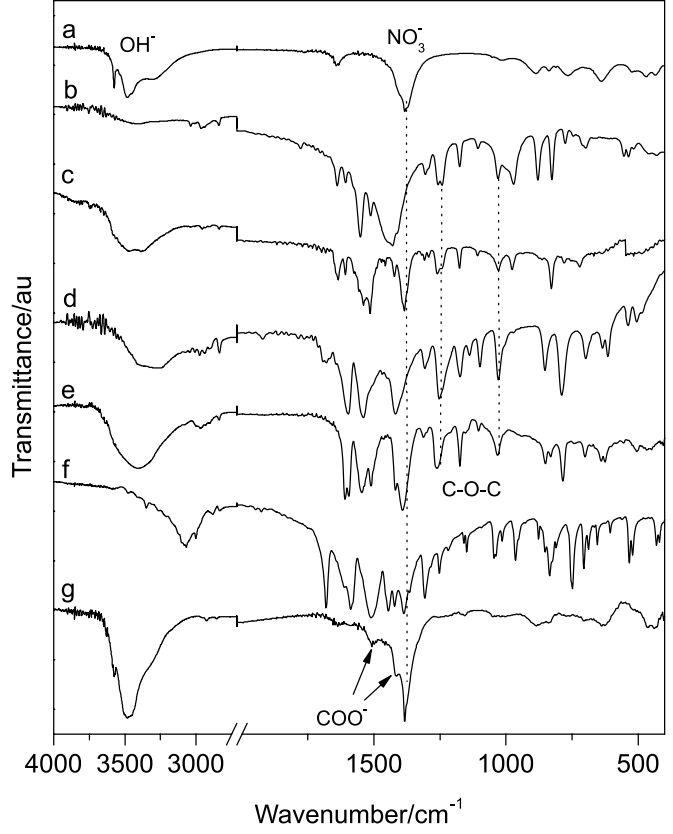

Figure 8. FTIR spectra of ZHN (a), sodium methoxycinnamate (b), ZHN-MC (c), sodium methoxybenzoate (d), ZHN-MB (e), sodium $\mathrm{N}$-acetylanthranilate (f) and ZHN-NAA (g).

Table 1. Wavenumbers $\left(\mathrm{cm}^{-1}\right)$ of some vibrational modes in the ZHN-MB and ZHN-MC compounds and the respective organic sodium salts

\begin{tabular}{llllll}
\hline Compound & $\mathrm{COO}^{-}{ }_{\text {(as) }}$ & $\mathrm{COO}_{\text {(sym) }}^{-}$ & $\mathrm{C}=\mathrm{C}_{\text {(arom) }}$ & $\mathrm{C}-\mathrm{O}-\mathrm{C}_{\text {(as) }}$ & $\mathrm{C}-\mathrm{O}-\mathrm{C}_{\text {(sym) }}$ \\
\hline Na-MC & 1554 & 1433 & 1512 & 1243 & 1033 \\
ZHN-MC & 1542 & 1423 & 1517 & 1259 & 1027 \\
Na-MB & 1596 & 1419 & 1541 & 1251 & 1029 \\
ZHN-MB & 1606 & 1417 & 1548 & 1259 & 1032 \\
\hline
\end{tabular}

(as) = Asymmetric stretching; $($ sym $)=$ symmetric stretching.

of the organic matter (exothermic event around $400{ }^{\circ} \mathrm{C}$ ). As discussed for the ZHN-DSD, the TGA/DTA analysis allows us to estimate the formula of the compounds as $\mathrm{Zn}_{5}(\mathrm{OH})_{8}\left(\mathrm{NO}_{3}\right)_{0.46}\left(\mathrm{C}_{10} \mathrm{H}_{9} \mathrm{O}_{3}\right)_{1.54} \cdot 3.4 \mathrm{H}_{2} \mathrm{O}$ for $\mathrm{ZHN}-\mathrm{MC}$ and $\mathrm{Zn}_{5}(\mathrm{OH})_{8}\left(\mathrm{NO}_{3}\right)_{0.48}\left(\mathrm{C}_{8} \mathrm{H}_{7} \mathrm{O}_{3}\right)_{1.52} \cdot 4.6 \mathrm{H}_{2} \mathrm{O}$ for $\mathrm{ZHN}-\mathrm{MB}$, where not all the nitrate anions were replaced by the organic anions. The adsorption of the $N$-acetylanthranilate anions onto ZHN is further attested by the TGA/DTA results (not shown), since they are clearly distinct from the thermal profile of the original ZHN.

The DRUV-VIS spectroscopic analysis of the ZHN-NAA compound (Figure 9d) presented absorption bands similar to those of the free acid (Figure 9c), its sodium salt (Figure 9b) and also the ZHN (Figure 9a).

However, in the UVA region, a shifted absorption maximum not seen in any of the precursors can be observed in the product. This is another indication that the UV-absorbing organic molecules are adsorbed on the ZHN particles outer surfaces. 


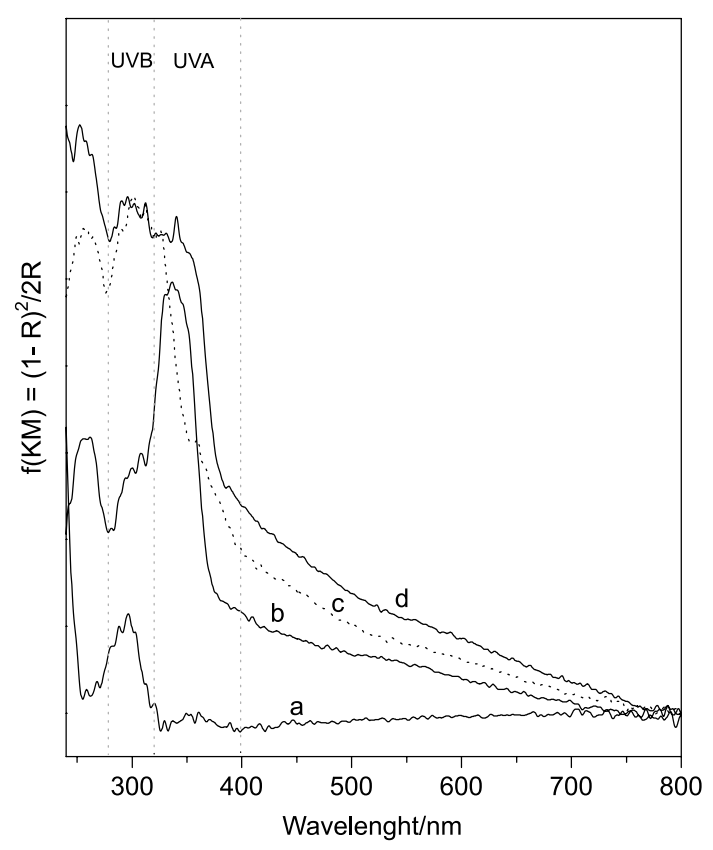

Figure 9. DRUV-VIS spectra of: ZHN (a), sodium $N$-acetylanthranilate (b), $\mathrm{N}$-acetylanthranilic acid (c) and ZHN-NAA (d).

The white-colored sodium 4-methoxybenzoate presented an absorption maximum around $250-290 \mathrm{~nm}$, covering the UVC to the UVB regions, as seen from the DRUV-VIS results (Figure 10d). After intercalation, the ZHN-MB product, also white, presented one absorption maximum around $253 \mathrm{~nm}$ (Figure 10e). Results from the DRUV-VIS spectroscopy analysis of the ZHN-MC compound (Figure 10c) presented one absorption maximum around $297 \mathrm{~nm}$, not absorbing in the visible region $(\lambda>400 \mathrm{~nm})$. This characteristic is possibly an advantage to the cosmetics industry, where colored additives are not always desired. In addition, this product absorbs in a broad spectral range, including UVC and UVB regions and a small part of the UVA region. This behavior is closely related to the sodium 4-methoxycinnamate, with an absorption range between 240 and $308 \mathrm{~nm}$ (Figure 10b), but significantly different than the 4-methoxycinnamic acid (not shown), with a maximum around 264-387 $\mathrm{nm}$.

As in the case of the ZHN-DSD compound, scanning electron microscopy images of the products obtained by co-precipitation (ZHN-MC) and exchange reaction (ZHN-NAA) (Figures $11 \mathrm{~b}$ and 11c) showed tabular particles with larger size and wider size distribution than those of ZHN (Figure 11a). The crystal growing process can be attributed to dissolution and re-precipitation during the exchange reaction.

The SAED pattern of the compounds obtained by coprecipitation confirmed that the basic structure is from the ZHN and the only difference between the products is the basal distance observed by XRD measurements

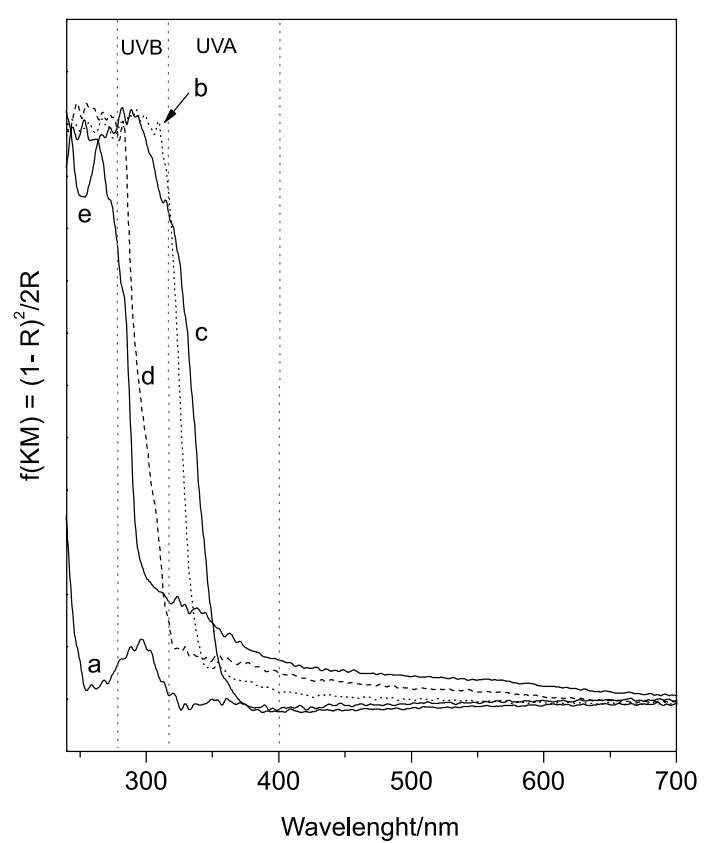

Figure 10. DRUV-VIS spectra of: ZHN (a), sodium 4-methoxycinnamate (b), ZHN-MC (c), sodium 4-methoxybenzoate (d) and ZHN-MB (e).
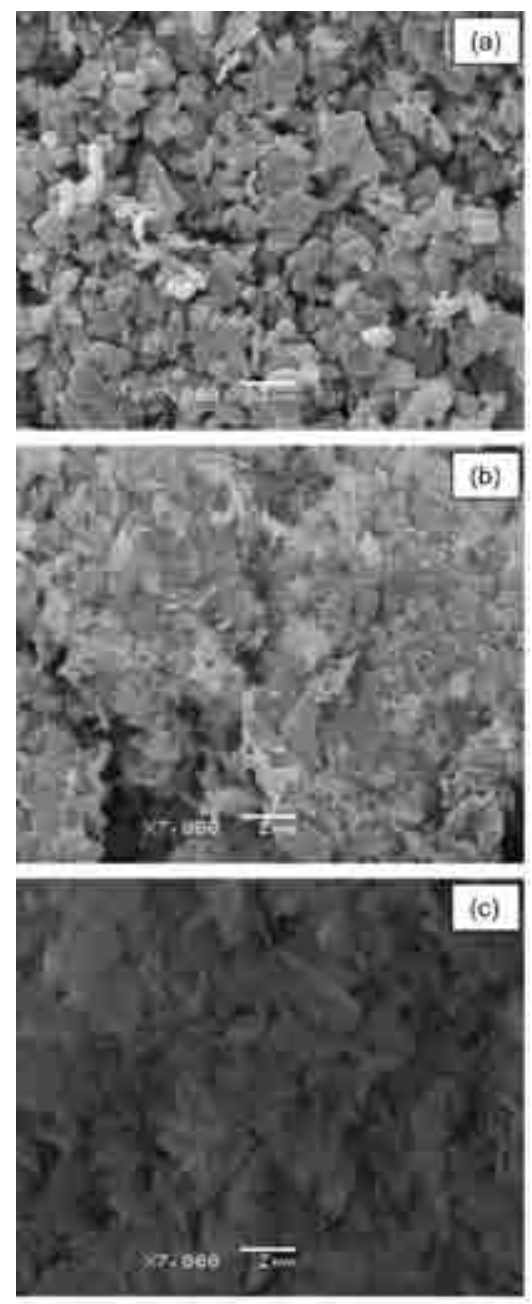

Figure 11. SEM images of: ZHN (a) ZHN-MC (b) and ZHN-NAA (c). 

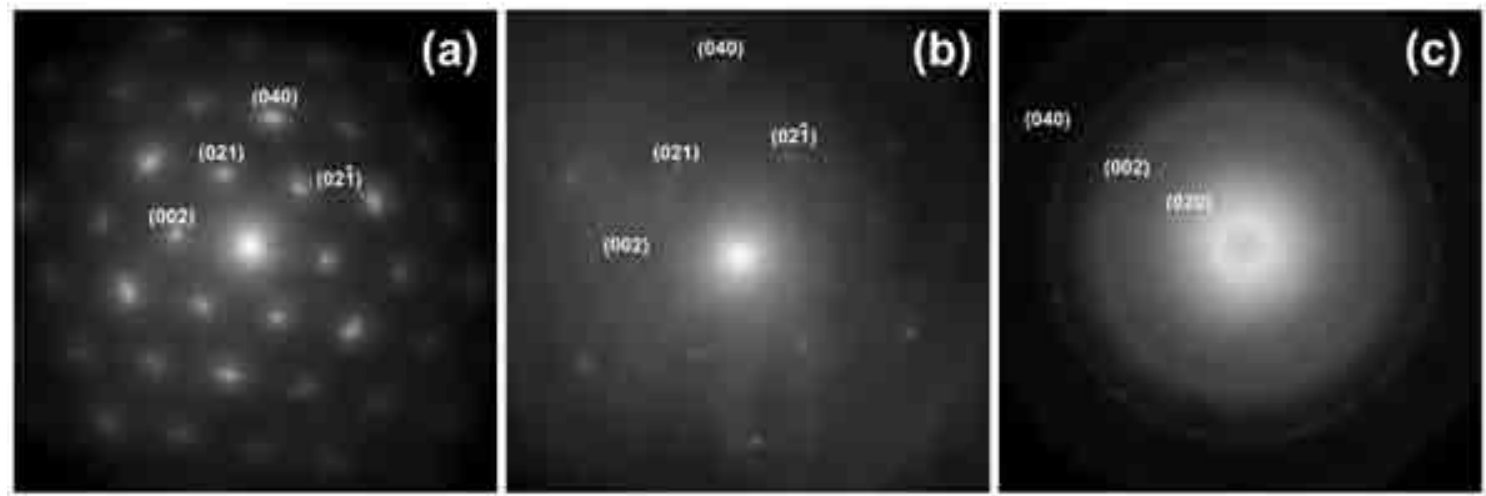

Figure 12. SAED pattern of ZHN obtained at $80 \mathrm{kV}$ and at room temperature (a), ZHN-DSD obtained at $50 \mathrm{kV}$ and at room temperature (b) and ZHN-MC obtained at $50 \mathrm{kV}$ at $-43{ }^{\circ} \mathrm{C}$ (c). The SAED pattern in (c) was obtained using a cooled specimen holder (Gatan model 636).

(see Figures 2 and 7). Figure 12 shows the standard SAED for the ZHN matrix and for the compounds obtained by coprecipitation. The ZHN matrix presented good structural stability to perform the analysis, as did the co-precipitated sample with stilbenedisulfonate (ZHN-DSD), both of them presenting large single crystals. In the case of the sample co-precipitated with methoxycinnamate (ZHN-MC), the crystals are too small, generating a standard polycrystal, as shown in Figure 12c. In addition, the structural stability of this sample is too low to be analyzed under normal conditions. The analysis then needs to be carried out at $-43{ }^{\circ} \mathrm{C}$ with a low-energy electron beam.

The indexed spots for the ZHN correspond to the non basal direction contributions, showing that the layer stacking occurs along the [100] axis. This crystallographic orientation is the same in all samples analyzed by SAED and no changes were observed in the spacing perpendicular to the layers. This shows that the stilbenedisulfonate and methoxycinnamate anions, in the co-precipitation process, are only intercalated between the layers, as observed by XRD in Figures 2 and 7, preserving the layer as in the ZHN structure. Probably the basal spacing of $20.13 \AA$ obtained for the sample co-precipitated with cinnamate reduces the cohesion between the layers, causing their low stability under the electron beam.

\section{Conclusion}

Layered zinc hydroxide nitrate was used as host for organic UV ray absorbing anions. 4-Methoxycinnamate, 4-methoxybenzoate and 4,4'-diamino-2,2'stilbenedisulfonate ions were intercalated between the ZHN layers, whereas the $\mathrm{N}$-acetylanthranilate anion was mostly likely adsorbed on the outer surfaces of the hydroxide salt particles. The products were characterized by XRPD, FTIR, TGA/DTA, DRUV-VIS spectroscopy, SEM and SAED. The results show that the organic-inorganic derivatives have interesting UV ray absorbing properties, sometimes even enhancing the absorption range of their precursors. Further research on these compounds could be very fruitful to the cosmetics industry, especially because zinc oxide is generally recognized as safe (GRAS) and is widely used as antiseptic and whitening pigment in cosmetic formulations.

\section{Acknowledgments}

We gratefully acknowledge the Brazilian Research Agencies CNPq, CAPES and FINEP for their financial support of this work. A. C. T. Cursino thanks CNPq for the masters research grant. We also acknowledge the use of the Electron Microscopy Center of the Federal University of Paraná.

\section{References}

1. Wissing, S. A.; Müller, R. H.; Int. J. Pharm. 2002, 242, 373.

2. Urbach, F.; J. Photochem. Photobiol., B 2001, 64, 99.

3. Agrapidis-Paloympes, L. E.; Nash, R. A.; Shaath, N. A.; J. Soc. Cosmet. Chem. 1987, 38, 209.

4. Costa, E. J.; Lacaz, E.; Med Cután Ibero-Latino Am. 2001, 29 , 145.

5. Hoyo, C.; Vicente, M. A.; Rives, V.; Clay Miner. 2001, 36, 541.

6. Perioli, L.; Ambrogi, V.; Bertini, B.; Ricci, M.; Nocchetti, M.; Latterini, L.; Rossi, C.; Eur. J. Pharm. Biopharm. 2006, 62, 185.

7. Perioli, L.; Nocchetti, M.; Ambrogi, V.; Latterini, L.; Rossi, C.; Costantino, U.; Microporous Mesoporous Mater. 2008, 107, 180; Costantino, U.; Ambrogi, V.; Nocchetti, M.; Perioli, L.; Microporous Mesoporous Mater. 2008, 107, 149.

8. Rietschel, R. L.; Fowler, J. F.; Fischer, A. A.; Fisher's Contact Dermatitis, $6^{\text {th }}$ ed., BC Decker Inc.: Ontario, 2008.

9. Cursino, A. C. T.; Gardolinski, J. E. F. C.; Wypych, F.; J. Colloid Interface Sci. 2010, 347, 49.

10. Hoyo, C.; Appl. Clay Sci. 2007, 36, 103. 
11. Feng, Y. J.; Li, D. Q.; Wang, Y.; Evans, D.G.; Duan, X.; Polym. Degrad. Stab. 2006, 91, 789.

12. Rossi, C.; Schoubben, A.; Ricci, M.; Perioli, L.; Ambrogi, V.; Latterini, L.; Aloisi, G. G.; Rossi, A.; Int. J. Pharm. 2005, 295, 47.

13. Xue, M.; Chitrakar, R.; Sakane, K.; Ooi, K.; Kobayashi, S.; Ohnishi, M.; Doi, A.; J. Solid State Chem. 2004, 177, 1624.

14. Nishizawa, H.; Yuasa, K.; J. Solid State Chem. 1998, 141, 229.

15. Marangoni, R.; Bubniak, G. A.; Cantão, M. P.; Abbate, M.; Schreiner, W. H.; Wypych, F.; J. Colloid Interface Sci. 2001, $240,245$.

16. Arizaga, G. G. C.; Satyanarayana, K. G.; Wypych, F.; Solid State Ionics 2007, 178, 1143.

17. Stählin, W.; Oswald, H. R.; Acta Crystallogr., Sect. B: Struct. Sci. 1970, 26, 860.

18. Newmann, S. P. Jones, W.; J. Solid State Chem. 1999, 148, 26.

19. Data Collection of the Joint Committee on Powder Diffraction Standard, PCPDFWIN, Version 2.2, Copyright, 2001.
20. Arizaga, G. C. G.; Mangrich, A. S. M.; Wypych, F.; J. Colloid Interface Sci. 2008, 320, 238.

21. Silverstein, R. M.; Webster, F. X.; Kiemle, D. J.; Spectrometric Identification of Organic Compounds, $7^{\text {th }}$ ed., J. Wiley \& Sons: Hoboken, USA, 2005.

22. Kubelka, P.; Munk, F.; Z. Tech. Phys. 1931, 12, 593.

23. Sherman, D. M.; Wait, T. D.; Am. Mineral. 1985, 70, 1262.

24. Chai, H.; Lin, Y. J.; Evans, D. G.; Li, D. Q.; Ind. Eng. Chem. Res. 2008, 47, 2855.

25. Cui, G. J.; Xu, X. Y; Yan, J. L.; Evans, D. G.; Dian, Q. L.; Ind. Eng. Chem. Res. 2010, 49, 448.

26 Wypych, F.; Arizaga, G. G. C.; Gardolinski, J. E. F. D.; J. Colloid Interface Sci. 2005, 283, 130.

27. Nakamoto, K.; Infrared and Raman Spectra of Inorganic and Coordination Compounds, $4^{\text {th }}$ ed., John Wiley \& Sons: New York, 1986. 


\section{Biotransformation of Sclareolide by Filamentous Fungi: Cytotoxic Evaluations of the Derivatives}

\section{Arturo Cano, ${ }^{a}$ María Teresa Ramírez-Apan ${ }^{b}$ and Guillermo Delgado ${ }^{*, b}$}

${ }^{a}$ Facultad de Estudios Superiores Zaragoza, Universidad Nacional Autónoma de México, Av. Guelatao $n^{\circ} .66$ (Eje 7 Oriente), Col Ejército de Oriente, Iztapalapa 09230, Mexico, D.F.

${ }^{b}$ Instituto de Química, Universidad Nacional Autónoma de México, Ciudad Universitaria, Circuito Exterior, Coyoacán 04510, Mexico, D.F.<smiles>CC1(F)C(O)CCC2C1C(O)CC1(C)OC(=O)C[C@]21C</smiles>

(16)

H.6

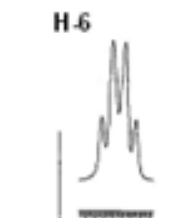

ppm

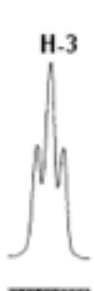

ppe
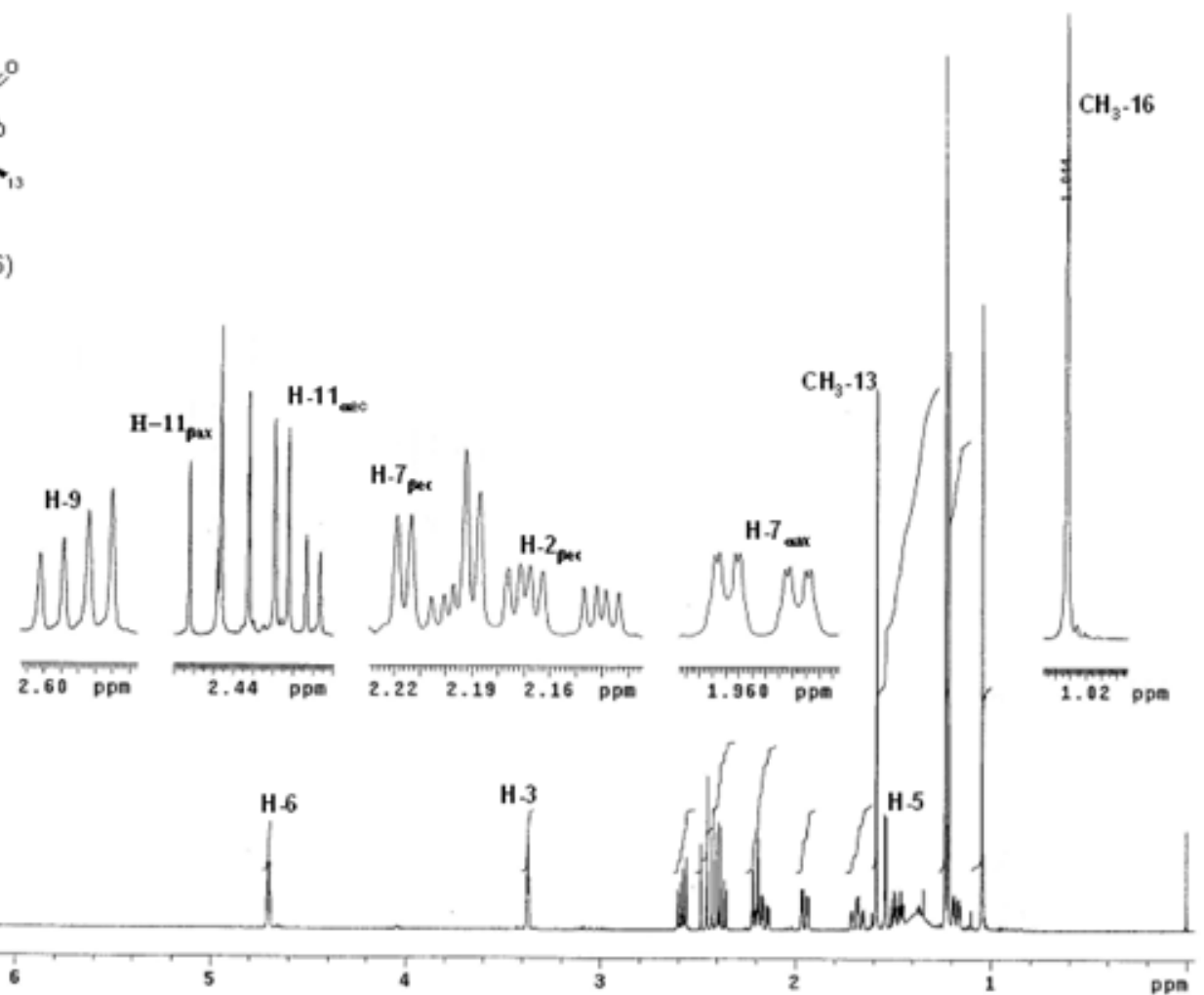

Figure S1. ${ }^{1} \mathrm{H}$ NMR $\left(500 \mathrm{MHz}, \mathrm{CDCl}_{3}\right)$ of $3 \alpha, 6 \beta$-dihydroxysclareolide (16). 

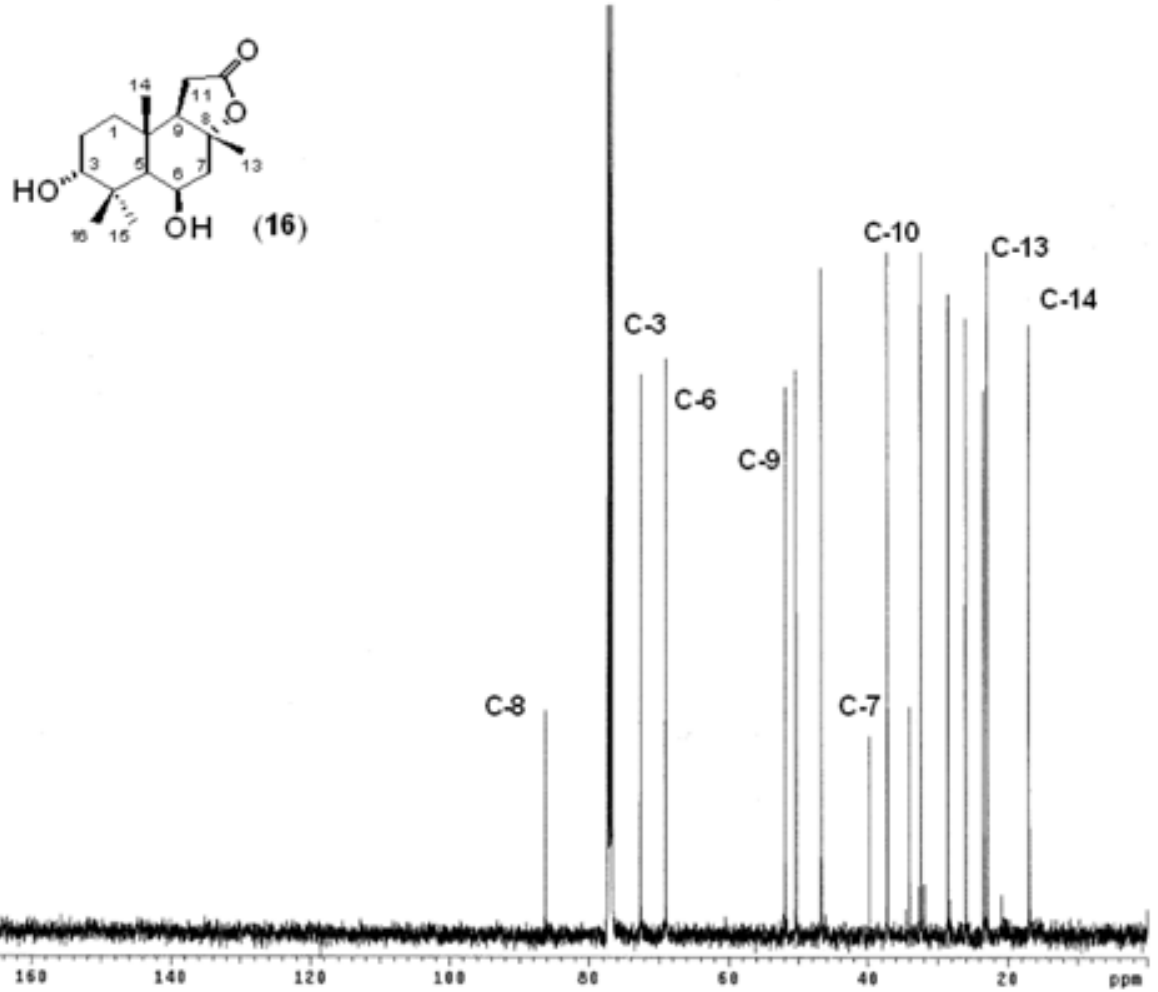

Figure S2. ${ }^{13} \mathrm{C}$ NMR $\left(125 \mathrm{MHz}, \mathrm{CDCl}_{3}\right)$ of $3 \alpha, 6 \beta$-dihydroxysclareolide (16).

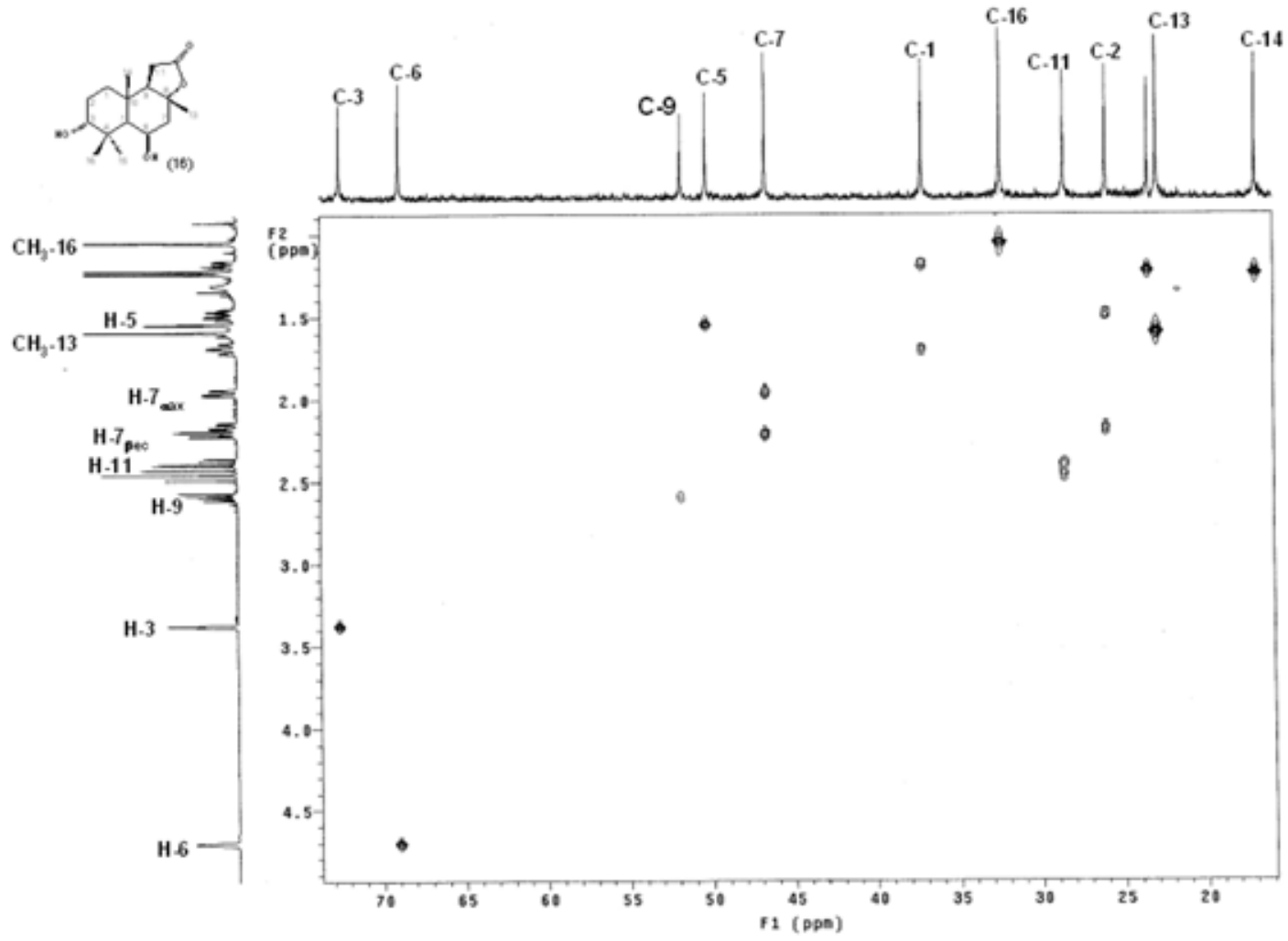

Figure S3. HSQC (500 MHz, $\mathrm{CDCl}_{3}$ ) of $3 \alpha, 6 \beta$-dihydroxysclareolide (16). 


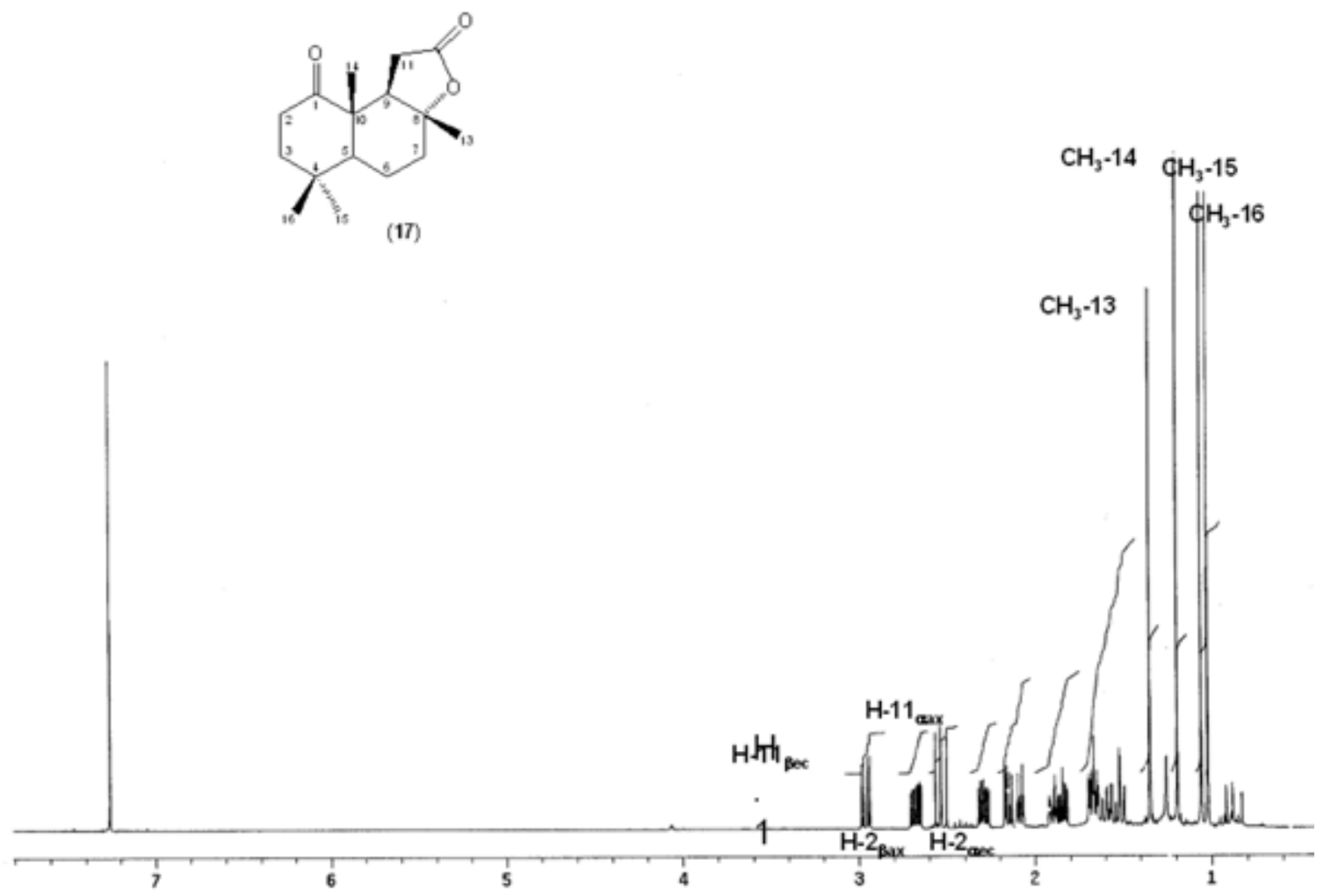

Figure S4. ${ }^{1} \mathrm{H}$ NMR (500 MHz, $\mathrm{CDCl}_{3}$ ) of 1-ketosclareolide (17).
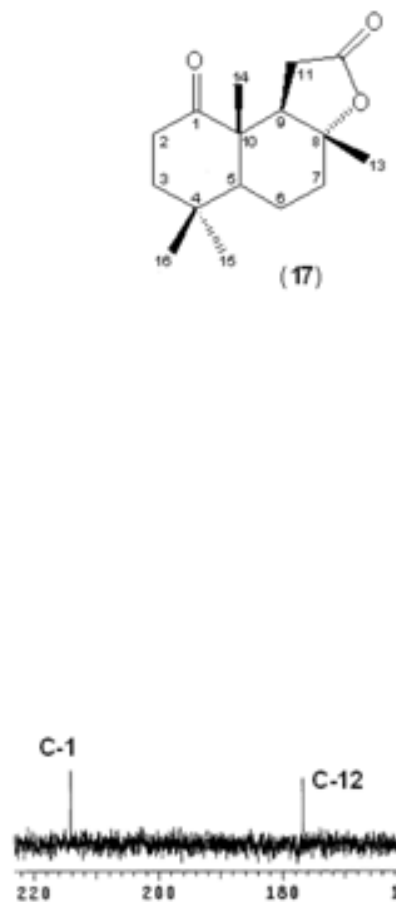

C-12

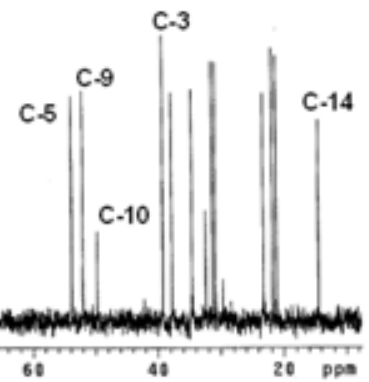

Figure S5. ${ }^{13} \mathrm{C}$ NMR $\left(125 \mathrm{MHz}, \mathrm{CDCl}_{3}\right)$ of 1-ketosclareolide (17). 


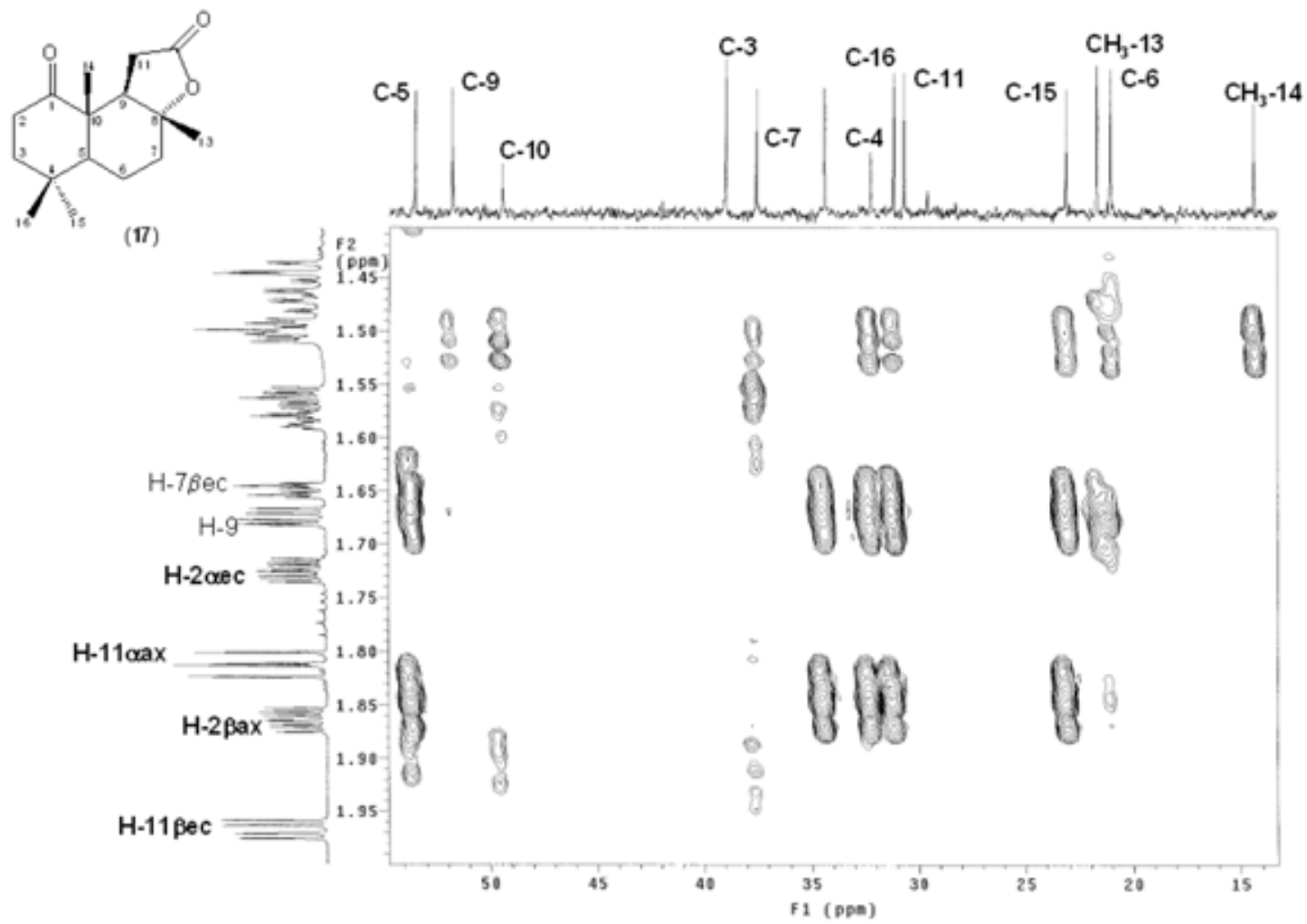

Figure S6. HMBC (500 MHz, $\mathrm{CDCl}_{3}$ ) of 1-ketosclareolide (17).
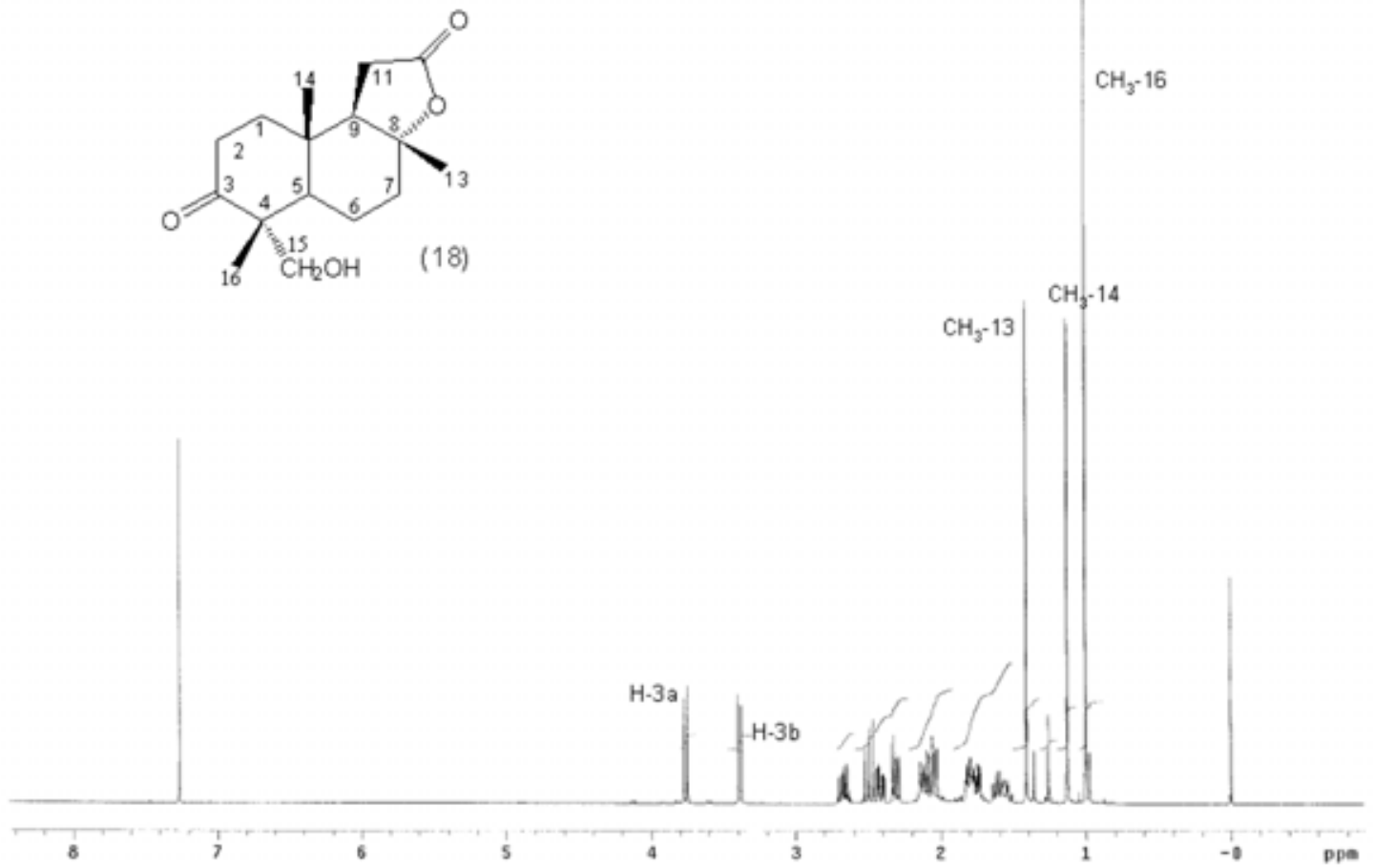

Figure S7. ${ }^{1} \mathrm{H}$ NMR (500MHz, $\mathrm{CDCl}_{3}$ ) of 3-keto-15-hydroxysclareolide (18). 

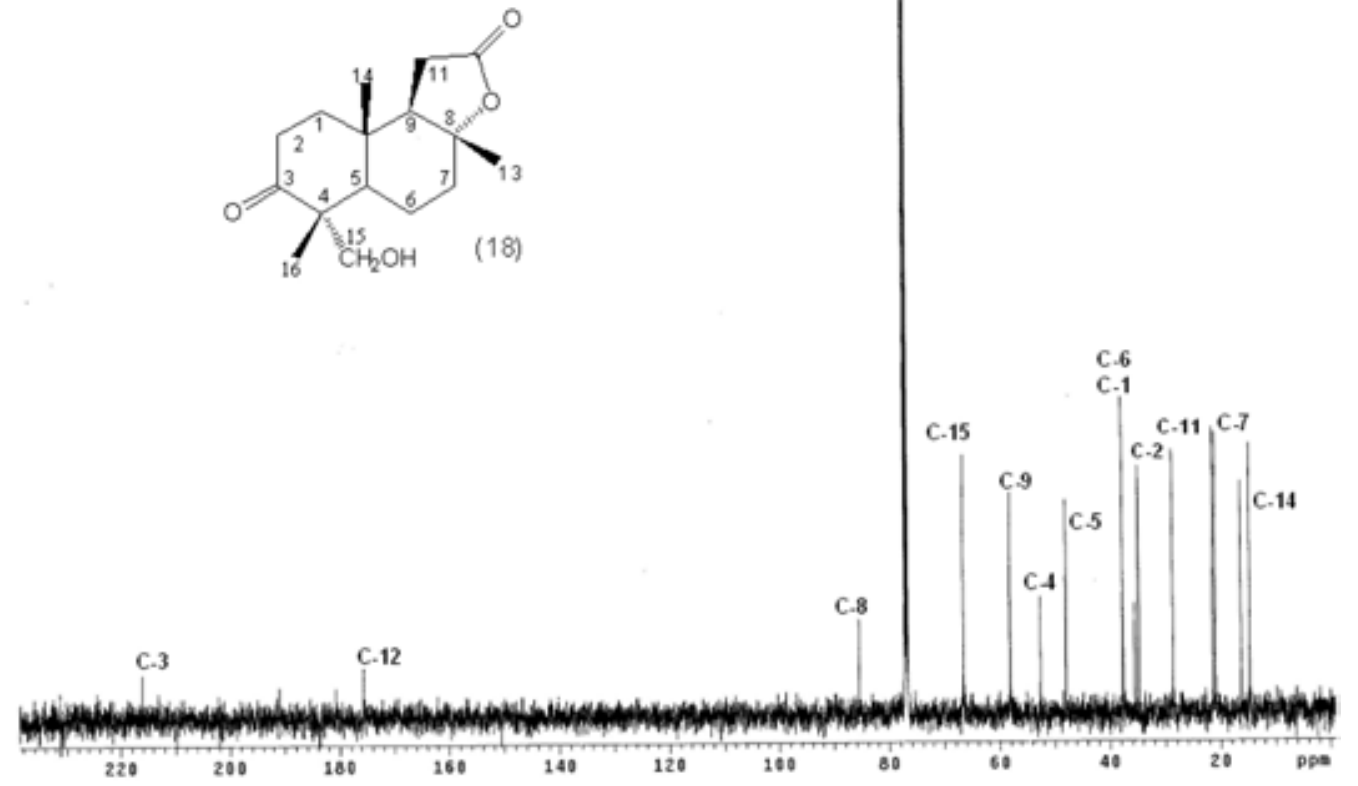

Figure S8. ${ }^{13} \mathrm{C}$ NMR (125 MHz, $\mathrm{CDCl}_{3}$ ) of 3-keto-15-hydroxysclareolide (18).

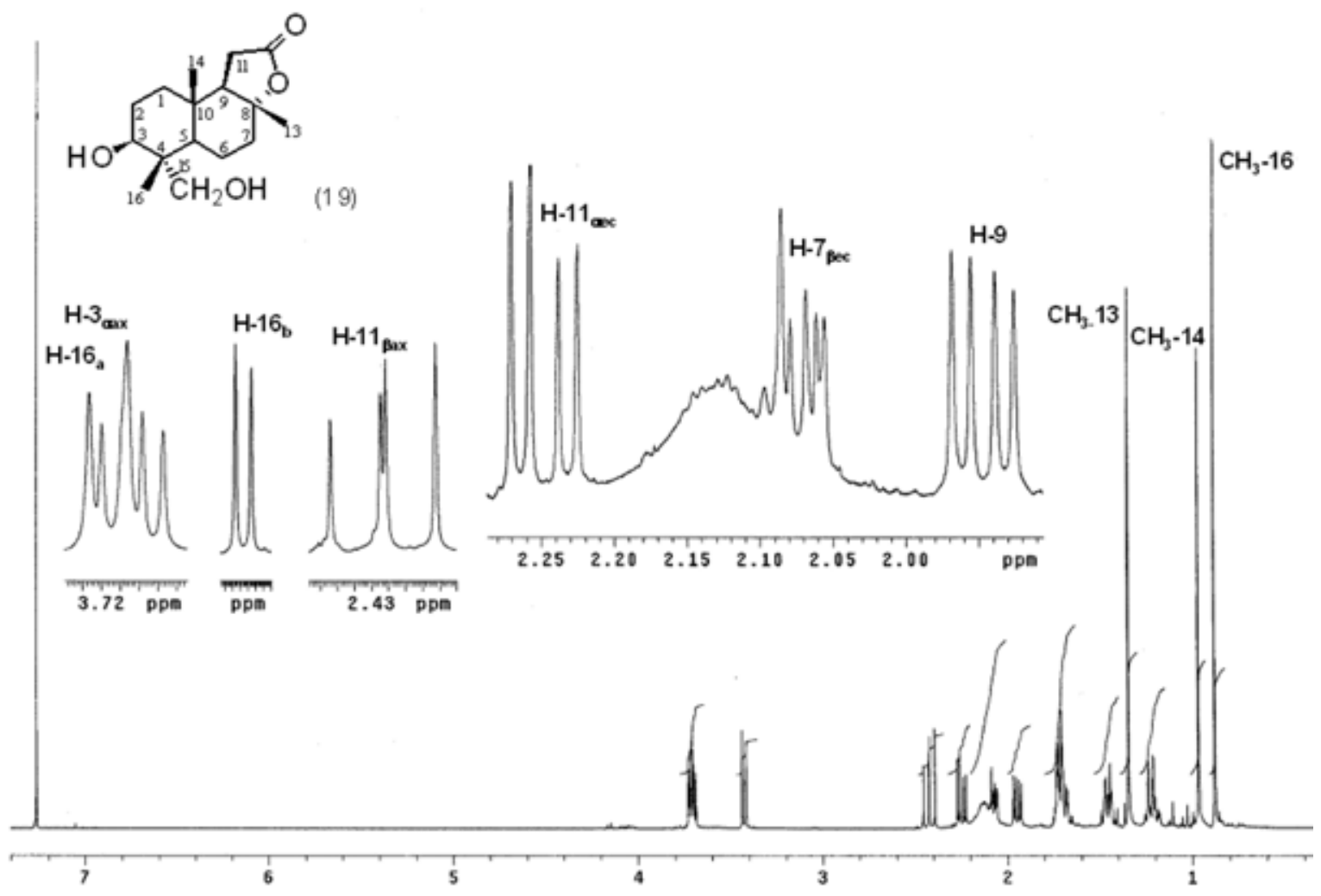

Figure S9. ' $\mathrm{H}$ NMR (500 MHz, $\mathrm{CDCl}_{3}$ ) of 3 $\beta$,15-dihydroxysclareolide (19). 

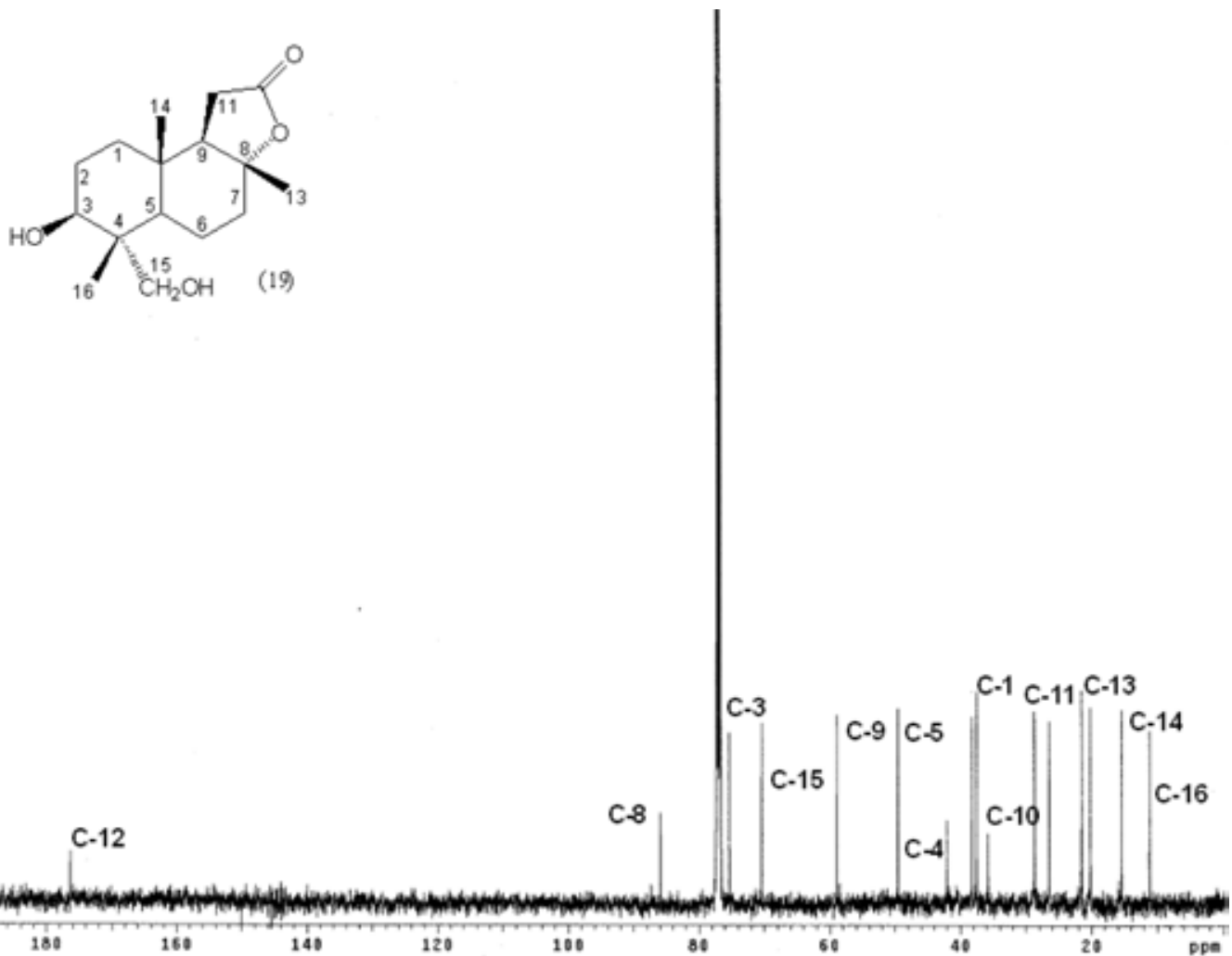

Figure S10. ${ }^{13} \mathrm{C}$ NMR $\left(125 \mathrm{MHz}, \mathrm{CDCl}_{3}\right)$ of 3 $\beta, 15$-dihydroxysclareolide (19).

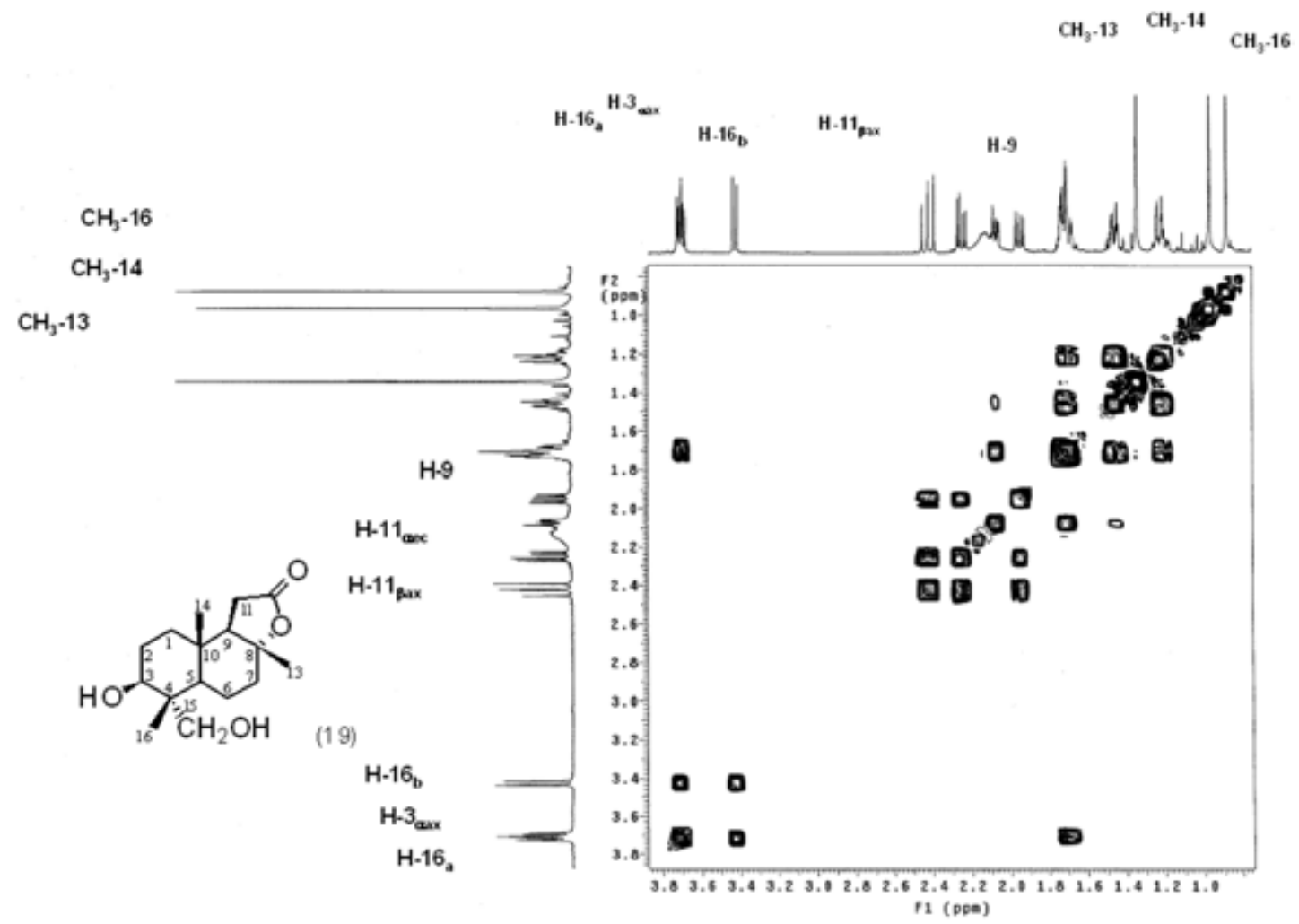

Figure S11. COSY Spectrum (500 MHz, $\mathrm{CDCl}_{3}$ ) of 3ß,15-dihydroxysclareolide (19). 


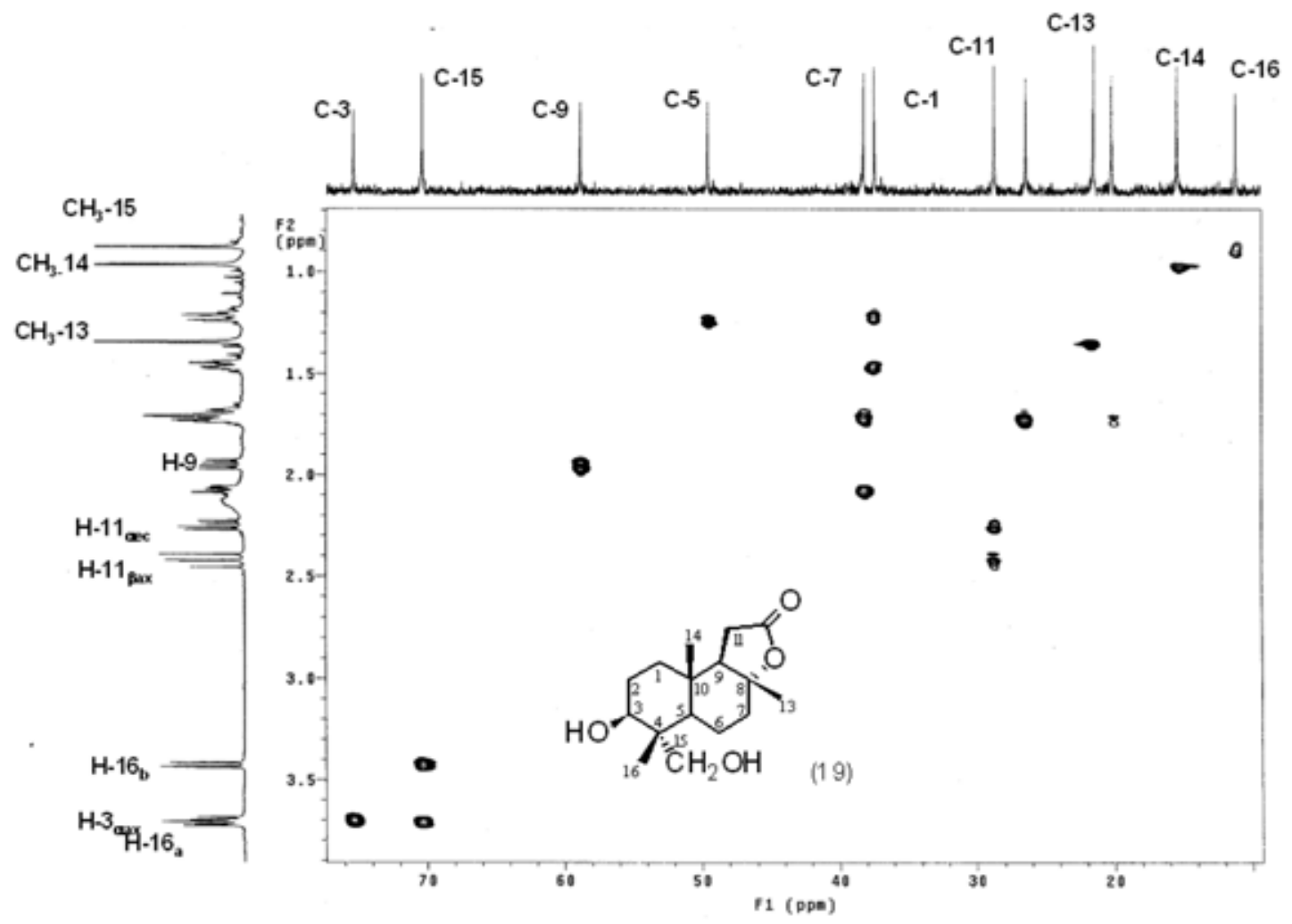

Figure S12. HSQC (500 MHz, $\mathrm{CDCl}_{3}$ ) of 3ß,15-dihydroxysclareolide (19). 